Bull. Mater. Sci., Vol. 8, No. 4, October 1986, pp. 527-530.

(C) Printed in India.

\title{
Determination of molecular weight distribution of polyethylene terephthalate by gelpermeation chromatography
}

\author{
K SREENIVASAN and PRABHA D NAIR \\ Biomedical Technology Wing, Sree Chitra Tirunal Institute for Medical Sciences and \\ Technology, Poojapura, Trivandrum 695012 , India. \\ MS received 18 March 1985; revised 25 April 1986

\begin{abstract}
Gel permeation chromatography was used to determine the molecular weight distribution of polyethylene terephthalate. Chloroform was used as the mobile phase. The average molecular weights calculated from the chromatogram closely agree with the known values of the samples used in this experiment.
\end{abstract}

Keywords. Polyethylene terephthalate; gel permeation chromatography; Styragel.

\section{Introduction}

A knowledge of molecular weight distribution (MWD) of a polymer is important for understanding the relationship between its structure and properties. Gel permeation chromatography (GPC) is commonly used for determining the MWD. However, the number of solvents which could be used for polyethylene terephthalate (PET) in conjuction with GPC is limited due to the insoluble nature of the polymer in most solvents. Phenols and mixed solvents containing phenols as one of the constituents have been widely used as solvents for PET (Panaris and Pallas 1970; Ede 1971; Didely 1972). The analysis requires, in certain cases, higher temperatures and often affects the detector response of the instrument. Moreover, the use of phenols as the mobile phase drastically affects the performance of the crosslinked polystyrene gels which are widely used as GPC column material (Snyder and Kirkland 1979). Recently hexafluoroisopropanol (HFIP) has been used as a GPC solvent for PET (Drott 1977). However, HFIP is incompatible with low pore size as well as old, crosslinked polystyrene packings (Drott 1977; Snyder and Kirkland 1979). Further the toxic hazards of HFIP are still not clearly known despite its wide use as a solvent for a variety of polymers. Also, the high cost of HFIP restricts its use as a routine solvent for PET.

In this paper, we describe a GPC method using chloroform as the mobile phase for determining the MWD and average molecular weights of PET.

\section{Experimental}

\subsection{Materials}

PET samples were from SITRA, India, Analytical grade phenol and chloroform from BDH, India. 


\subsection{Method}

About $25 \mathrm{mg}$ of the PET samples were dissolved in $10 \mathrm{ml}$ of chloroform-phenol mixture $(1: 1 \mathrm{~V} / \mathrm{V})$ at about $50^{\circ} \mathrm{C}$. One $\mathrm{ml}$ of this solution was diluted with $4 \mathrm{ml}$ of chloroform and filtered through a millipore membrane. $100 \mu \mathrm{l}$ of the solutions were used for the analysis.

\subsection{Chromatography}

The instrument employed consisted of a solvent delivery pump (Waters Associates Model 6000A), 440 absorbance detector, U6K injector and a set of five $\mu$ Styragel columns of pore size $10^{5}, 10^{4}, 10^{3}, 500$ and $100 \AA$ (particle size $10 \mu \mathrm{m}$ ). Freshly distilled chloroform at a flow rate of $1 \mathrm{ml} / \mathrm{min}$ was used as the mobile phase and columns effluents were monitored at $254 \mathrm{~nm}$. The columns were calibrated using polystyrene standards (Waters Associates Inc, USA) in chloroform.

\subsection{Calibration curve}

$0.1 \%$ solutions of polystyrene standards in chloroform were prepared. Peak average molecular weights of the standards chosen were $2,40,000,1,10,000,50,000,9,000$ and 4,000. These solutions were filtered and $100 \mu \mathrm{l}$ of the filtered solution were injected into the chromatograph. Chromatography was performed under the same conditions as used for the samples above. The retention time of each standard i.e. from the start of the injection to the maximum of the chromatographic peak was plotted on the linear $\mathrm{x}$-axis on semilog paper vs the corresponding value on the logarithmic $y$-axis of the peak molecular weight of the respective standard. A smooth curve was drawn through the points plotted to obtain the calibration curve.

\subsection{Computation}

The direct calibration method was employed for determining the weight average molecular weight of the PET samples. The data obtained were computed as in DSO (1974). The retention times for the start $\left(t_{1}\right)$ and finish $\left(t_{2}\right)$ of the polymer chromatogram were marked and a baseline drawn from $t_{1}$ to $t_{2}$. Peak heights of 15 equally spaced points along the GPC curve were measured and tabulated under the headings: col.1: retention time; col.2: height $(\mathrm{mm})$; col.3: molecular weight; col.4: col.2/col.3; col.5: col. $2 \times$ col.3. The molecular weight averages were determined by the following equations

$$
\begin{aligned}
& M_{n}=\Sigma \text { col. } 2 / \Sigma \text { col. } 4, \\
& M_{w}=\Sigma \text { col. } 5 / \Sigma \text { col. } 2 .
\end{aligned}
$$

The equations are based on the theoretical equation

$$
\bar{M}^{*}=\sum_{0}^{i} N i M i^{b} / \sum_{0}^{i} N i M i^{b-1},
$$

Where $b$ is a constant, any whole integer, and $\bar{M}^{*}=M_{n}$, when $b=1, M_{w}$ when $b=2$, $M_{z}$ when $b=3$, respectively. 


\section{Results and discussion}

Figure 1 shows a typical chromatogram of PET in the mobile phase. The number average and the weight average molecular weights were determined from the chromatogram according to the method discussed above and summarized in table 1.

Table 1 also gives the known values of viscosity average molecular weights $M_{v}$ of the three PET samples A, B and C. The molecular weights obtained by the GPC method can be said to be in good agreement with the known values of $M_{v}$ as it is known that $M_{v}$ lies between $M_{n}$ and $M_{w}$ but closer to $M_{w}$ (Allcock and Lampe 1981).

PET is widely used commercially and as a biomedical polymer. In this context, it should be noted that subtle batch-to-batch variation in MWD and molecular weights of PET can cause significant differences in end use performances. The

Table 1. Molecular weights of PET samples

\begin{tabular}{ccccc}
\hline Sample & $\begin{array}{c}\text { Number average } \\
\text { molecular } \\
\text { weight }\left(M_{n}\right)\end{array}$ & $\begin{array}{c}\text { Viscosity } \\
\text { average } \\
\text { molecular } \\
\text { weight }\left(M_{v}\right)\end{array}$ & $\begin{array}{c}\text { Weight average } \\
\text { molecular } \\
\text { weight }\left(M_{w}\right)\end{array}$ & $\begin{array}{c}\text { Dispersity } \\
\left(M_{w} / M_{n}\right)\end{array}$ \\
\hline A & 24,000 & 54,767 & 58,175 & $2 \cdot 42$ \\
B & 25,000 & 40,553 & 54,669 & $2 \cdot 19$ \\
C & 24,009 & 56,099 & 62,147 & $2 \cdot 59$ \\
\hline
\end{tabular}

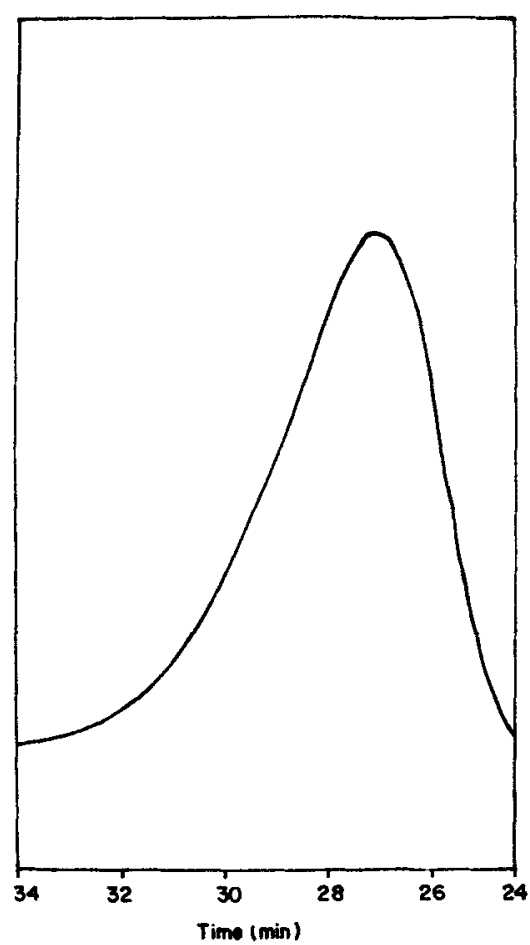

Figure 1, A representative chromatogram of PET. 
dependability of a number of properties such as mechanical strength, glass transition temperature etc on MWD and molecular weight further emphasize the need for a simple and rapid method for the determination of molecular weights and dispersity.

Light scattering and viscometric methods, which are also used for molecular weight determinations, however require extensive sample preparation and are too cumbersome for routine determinations. Further, these techniques are incapable of providing any information on MWD.

The hydrodynamic volume of PET molecules in chloroform relative to the conformational status in other good solvents and solvent mixtures has not been assessed. However, the close agreement of the data obtained from the present method with the known values of the viscosity average molecular weight of the samples indicates the absence of any substantial deviation of molecular size in chloroform.

A small quantity of phenol introduced along with the samples elutes after a considerable time and does not interfere with the analysis.

\section{Conclusion}

The reported method allows the MWD determination of PET at ambient temperature without affecting the efficiency of the crosslinked polytyrene gel columns.

\section{Acknowledgement}

The authors thank Mr G S Bhuvaneshwar for the PET samples.

\section{References}

Allcock H R and Lampe F W 1981 Contemporary polymer chemistry (New Jersey: Prentice-Hall) p. 388 Didely M A 1972 J. Appl. Polym. Sci. 16493

Drott E E 1977 Chromatographic science series (ed.) Jack Cazes (New York: Marcel-Dekker) Vol. 8, p. 41 DSO 1974 Waters Associates Application brief, DSO 47, April

Ede P S 1971 J. Chromatogr. Sci. 9275

Panaris R and Pallas G 1970 J. Polym. Sci. 16493

Snyder L R and Kirkland J J 1979 Introduction to modern liquid chromatography (New York: WileyInterscience) $\mathrm{Ch} .12$ 